\title{
The First Investigation of Tick Vectors and Tick-Borne Diseases in Extensively Managed Cattle in Alle District, Southwestern Ethiopia
}

\author{
Asrat Solomon $\left.{ }^{10}\right)^{1,2}$ and Bereket Molla Tanga $\mathbb{i}^{1,3}$ \\ ${ }^{1}$ Faculty of Veterianry Medicine, Hawassa University, P.O. Box: 05, Hawassa, Ethiopia \\ ${ }^{2}$ Alle District Livestock and Fisheries Development, Alle, Ethiopia \\ ${ }^{3}$ College of Veterianry Medicine, Chungnam National University, Daejeon, Republic of Korea
}

Correspondence should be addressed to Bereket Molla Tanga; mollabereket@gmail.com

Received 1 September 2020; Revised 23 November 2020; Accepted 27 November 2020; Published 21 December 2020

Academic Editor: Francesca Mancianti

Copyright ( 2020 Asrat Solomon and Bereket Molla Tanga. This is an open access article distributed under the Creative Commons Attribution License, which permits unrestricted use, distribution, and reproduction in any medium, provided the original work is properly cited.

\begin{abstract}
A cross-sectional study was conducted from March 2019 to February 2020 with the objective of identifying ixodid ticks and haemoparasites, in extensively managed livestock, in Alle district, Southwestern Ethiopia. The study area is assumed to be free from ticks, and there had been no diagnostic and treatment options for tick-borne diseases. Among 384 heads of cattle examined for tick infestation and haemoparasites, 139 (36.19\%) were infested with one or more tick species and 25 (6.51\%) were haemoparasitised. Two genera of ticks, Amblyomma and Rhipicephalus formerly (Boophilus), and four species (Amblyomma variegatum, Amblyomma lepidum, Rhipicephalus microplus, and Rhipicephalus annulatus) were identified. The haemoparasite identified was Babesia bovis. Among the risk factors, body condition score and season of the year were found to be significantly associated with tick infestation with $x^{2}=9.919, p>0.05$ and $x^{2}=6.216, p>0.05$, respectively, at $95 \%$ CI. Tick infestation was found to be significantly associated with haemoparasitemia with $x^{2}=22.2$ and $p>0.05$, at $95 \%$ CI. The finding of the current study is an alarm ring, as the veterinary service had been not considering any haemoparasitemia in the potential list of differential diagnosis and no treatment inputs have been availed for that purpose. Thus, it is recommended that the veterinary service delivery system in the area should take haemoparasites diagnosis and avail treatment alternatives, particularly tick-borne diseases. Furthermore, there should be a strategical approach in controlling tick-borne diseases in the area before the tick-borne diseases get prevalent and where the control after high prevalence could not be easy in extensive livestock management.
\end{abstract}

\section{Introduction}

Ethiopia possess huge number of livestock populations with an estimated 57.83 million cattle, 29.33 millions of sheep, 29.11 millions of goats, 1.16 million of camels, 9.86 millions of equines, and 56.87 millions of chickens which represent an immense economic potential [1]. Despite this huge resource, it contributes limited share of household and national economy in the country [2].

Ticks are small, wingless ectoparasitic arachnid arthropods that are cosmopolitan and prevalent in warmer climate [3]. Ixodid ticks are one of the most common and harmful blood sucking ectoparasites of cattle worldwide. They are responsible for a wide range of livestock health problems in several countries of the world. They reduce the cattle productivity, milk yield, and skin and hide quality and increase susceptibility to other diseases [4].

Ticks are harmful blood sucking external parasites of livestock that are distributed in all agroecological zones in Ethiopia [5]. Hard ticks (Acari, Ixodidae) are ubiquitous blood feeding ectoparasites that infest human and animals and are vectors of pathogenic microorganisms of rickettsial, bacterial, viral, and protozoal origin that cause severe infectious diseases in humans and livestock [6].

Tick-borne pathogens affect $80 \%$ of the world's cattle population and are widely distributed throughout the world, particularly in the tropics and subtropics [7]. According to [8], ticks which are considered to be the most important to 
the health of domestic animal in Africa comprise about seven genera. Among these genera, the main tick genera found in Ethiopia includes Amblyomma, subgenus Rhipicephalus (Boophilus), Haemaphysalis, Hyalomma, and Rhipicephalus. The genus Amblyomma and Rhipicephalus are predominating in many parts of the country, and Hyalomma and subgenus Rhipicephalus (Boophilus) also have a significant role [9].

In Ethiopia, there are 47 species of ticks found on livestock and most of them have importance as vector and disease-causing agents and also have a damaging effect on the skin and hide production as reviewed by [10]. Among several tick species widely distributed in Ethiopia, the major tick genera reported are Amblyomma, Rhipicephalus (Boophilus), Hyalomma, and Haemaphysalis [11]. The country' environmental condition and vegetation are highly conducive for ticks and tick-borne disease maintenance [12]. Acaricide application is still the main method of tick control in Ethiopia [13]. Currently, organophosphates are the most widely used chemicals although evidence of resistance is emerging [14].

Tick-borne diseases are one of the most constraints to livestock production in developing countries. The most important tick-borne diseases in sub-Saharan Africa are theileriosis caused by Theileria parva, babesiosis caused by Babesia bovis and Babesia bigemina, anaplasmosis caused by Anaplasma marginale, and heart-water caused by Ehrlichia ruminantium [15].

Rhipicephalus is the principal vector for Babesia bovis and Babesia bigemina. The vectors are widely spread in tropical and subtropical countries [16]. Tropical theileriosis also known as Mediterranean Coast Fever is extremely fatal and debilitating tick-transmitted disease infecting cattle [17]. The two most pathogenic and economically important Theileria species are Theileria parva and Theileria annulata [18]. Bovine theileriosis is reported in Ethiopia for the first time in the recent study by Gebrekidan et al. [19] in which four species of Theileria such as Theileria velifera. Theileria mutans, Theileria orientalis complex, and Theileria annulata were identified in cattle in Humera.

Bovine anaplasmosis is one of the most important vector-borne infectious diseases in cattle mainly caused by Anaplasma marginale and rarely by Anaplasma centrale. The organisms are Gram-negative obligate intracellular rickettsial bacteria [20], classified in the genus Anaplasma, belonging to the family Anaplasmataceae of the order Rickettsiales [21]. Anaplasma phagocytophilum has been recognized as an animal pathogen and is an emerging human pathogen of public health relevance [22].

There are different routes of haemoparasite transmission; the main route is by ticks which act as vectors for many haemoprotozoal diseases such as Babesia, Theileria, and Anaplasma [23]. Other routes include intrauterine, colostral, and mechanical transmission [24].

Due to economic and veterinary importance of ticks, their control and transmission of tick-borne diseases remain a challenge for the cattle industry of the world, and it is priority for many countries in tropical and subtropical regions [25]. Ticks are effective disease vectors, second only to mosquitoes in transmitting infectious diseases [26]. Haemoparasites have a great economic impact on livestock affecting $80 \%$ of the world cattle population and causes economic loss due to morbidity and mortality. They also impair the export and import trade of live animal and animal products by downgrading their quality [27].

Among livestock, cattle play a significant socioeconomic role in the livelihoods of the Ethiopian people [28]. Ticks and tick-borne diseases affect the productivity of cattle and leads to a significant adverse impact on the livelihoods of resource poor farming communities [29].

The importance of strategies to control the diseases requires more detailed knowledge of their prevalence and how they interact with each other [30]. No study has been conducted regarding identification of ixodid ticks and tickborne haemoparasites in this area. And there were no diagnostic and treatment approaches in place even to detect whether there is a problem or not. Therefore, the current study was aimed to investigate cattle ixodid ticks and tickborne haemoparasite in Alle district.

\section{Materials and Methods}

2.1. Study Area. Alle district located $650 \mathrm{~km}$ from Addis Ababa, the capital, with an altitude of 590-2800 meters above sea level and annual rain fall ranges from $800 \mathrm{~mm}$ to $1500 \mathrm{~mm}$. The weather condition of the area is arid (35\%), semiarid (47\%), and humid (18\%), which makes the area suitable for production of different crops [31]. The temperature ranges from $20^{\circ} \mathrm{C}$ to $23^{\circ} \mathrm{C}$ [31]. The livestock population of Woreda has a total head of 509,551 cattle, 511,107 goats, 78,765 sheep, 18,534 donkeys, 519 horses, 383 mules, and 227,846 chickens [31].

2.2. Study Population. The target population was all cattle in the 7 kebeles, the lowest administrative units, in Alle district. The sample population was randomly selected cattle from animals coming to veterinary clinics and working and resting places in Alle district.

\subsection{Sampling Method and Sample Size Determination.}

The sample size was determined according to the random sampling approach. $5 \%$ of desired absolute precision at the confidence level of $95 \%$ was used. Since no study was conducted in this area regarding this topic, 50\% prevalence was used. The sample size was determined using the equations given by Thrusfield [32].

Whereby,

$$
n=\frac{Z^{2}-P Q}{e^{2}},
$$

where $Q=1-P, Z=1.96, e=$ precision error (0.05), and $P=$ expected prevalence of about $50 \%$. Therefore, $n=1.96^{2} \times(0.5)(1-0.5) /\left(0.05^{2}\right)=384$. 
2.4. Study Design and Methodology. A cross-sectional study was conducted on cattle to determine the prevalence of ixodid ticks and tick-borne haemoparasites in cattle in Alle district from March 2019 to February 2020.

2.4.1. Collection and Identification of Ticks. The entire body surface of the cattle was inspected for the presence of ticks. After fully restraining the animals, all visible adult tick species were removed by hands and using forceps holding the basis capitulum, so as not to lose the mouth parts of the ticks. Ticks from each animal were collected and placed in separate prelabeled universal bottles containing $10 \%$ formalin solution until identification.Date of collection, age of animal, sex of animal, body condition score (BCS), and season of the year were recorded as well. The age of animals was grouped as young (between 1 and 3 years) and adults ( $>3$ years) according to the classification method used by [33], while body condition scores of animals were evaluated during sample collection. They were classified as emaciated (poor), moderate (medium), and good based on anatomical parts and the flesh and fat cover at different body parts [34]. Extremely lean, having prominent dorsal spines pointed to touch and individual visible transverse processes into which a finger could be easily pushed, was considered as a poor body condition score. A medium body condition score cattle was expressed as having visible ribs with little fat cover and barely visible dorsal spines. A good body condition score was given for the animals when fat cover was easily seen in critical areas and felt and the transverse processes were seen or felt. Ticks were counted and subsequently identified to the genus level and species level by using a direct stereomicroscope using key morphological characteristic, i.e., size of mouth parts, color of the body, leg color, presence or absence of the eye, shape of scutum, body, coxae one, festoon, and ventral plates were considered as described by Walker et al. [8].

2.4.2. Collection and Examination of Blood Sample. Blood film examination was performed with Giemsa staining procedures, and microscopic examination of slides was conducted according to [35]. Blood was taken from the ear veins, and thin blood smears were made and labeled. The slide was then air dried and immediately fixed with absolute methyl alcohol for few seconds, and then, the smear was stained with $10 \%$ Giemsa stain. Finally, the slides were thoroughly examined under a compound microscope using oil immersion. The parasites searched for include Babesia species (spp.), Anaplasma spp., and Theileria spp.

2.5. Data Management and Analysis. The data collected were stored in the Microsoft Excel Spreadsheet and analyzed by using Stata Version 13. Descriptive statistics were used to summarize the data. The prevalence was calculated as the total infestation/infection cases divided by the total cattle examined. Pearson's chi-square statistics were used to test the association between variables. $P$ value less than 0.05 at $95 \%$ confidence level was considered as significance cut value in interpreting the results.

\section{Results}

In this study, a total of 384 cattle were examined. Two tick genera, Rhipicephalus and Amblyomma, and four tick species were identified. The tick species identified were Amblyomma variegatum (A. variegatum), Amblyomma lepidum (A. lepidum), Rhipicephalus microplus (R. microplus), and Rhipicephalus annulatus (R. annulatus) in order of relative infestation rates as shown in Table 1 . The breeds of animals examined were 380 (98.95\%) local, 1 exotic $(0.26 \%)$, and $3(0.78 \%)$ crossbreed's.

3.1. Prevalence of Ixodid Ticks. Among 384 cattle examined for tick infestation, 139 (36.19\%) were infested with ticks. The tick genera identified are illustrated in Table 2. Prevalence of ticks varied in different kebeles of the study area. Highest prevalence was observed in Guma kebele (57.44\%), followed by Gawada (41.9\%), and lowest prevalence was observed at Addis Oltima kebele (19.04\%) (Table 3).

3.2. Risk Factors Associated with Ixodid Tick Infestation. Age, sex, and breed were not significantly associated with tick infestation, whereas the body condition score and season of the year were found statistically significantly associated with tick infestation in cattle. The prevalence of tick infestation was higher in older, female, and exotic breed of animals, though it is not statistically significant. Regarding the body condition score and season, tick infestation was higher in poor body condition animal and in wet season of the year (Table 4 ).

3.3. The Prevalence of Haemoparasites. Among 384 cattle examined for tick-transmitted haemoparasites parasitism, 25 (6.51\%) were found parasitized. Among the 25 animals having haemoparasites, majority, $20(80 \%)$ were infested with ticks during the study period. The haemoparasite identified is Babesia bovis in all animals tested positive (Table 5).

3.4. Risk Factors Associated with the Prevalence of Haemoparasites. Age, sex, body condition score, breed, and season were not statistically significantly associated with haemoparasitism. Only tick infestation of animals was found statistically significantly associated with haemoparasitism. Higher prevalence of haemoparasitism was observed in old, female, medium body conditioned, and local breed animals, eventhough it is not statistically significantly different. Regarding seasonal variation of tick infestation, the prevalence was found higher in wet season than dry season of the year (Table 5).

\section{Discussion}

The current study identified the overall prevalence of $36.19 \%$ of tick infestation in cattle in Alle district, which is lower 
Table 1: Prevalence of tick based on species observed.

\begin{tabular}{lcc}
\hline Species of tick & Frequency $(\mathrm{n})$ & Percentage $(\%)$ \\
\hline A. variegatum & 76 & 54.67 \\
A. lepidum & 13 & 9.35 \\
R. microplus & 27 & 19.4 \\
R. annulatus & 11 & 7.9 \\
Mixed & 12 & 8.63 \\
Total & 139 & 36.19 \\
\hline
\end{tabular}

TABle 2: Prevalence of tick based on the genera observed.

\begin{tabular}{lccc}
\hline No. & Species of tick & Frequency $(\mathrm{n})$ & Percentage $(\%)$ \\
\hline 1 & Amblyomma & 89 & 23.17 \\
2 & Boophilus & 38 & 9.895 \\
3 & Mixed & 12 & 3.125 \\
& Total & 139 & 36.19 \\
\hline
\end{tabular}

TABLE 3: Prevalence of tick at kebeles observed.

\begin{tabular}{lccc}
\hline Name of kebele & Number examined & Number & Percentage $(\%)$ \\
\hline Wolango & 91 & 35 & 38.46 \\
Guma & 47 & 20 & 57.44 \\
Gawada & 62 & 26 & 41.9 \\
Kerkerte & 62 & 26 & 41.9 \\
Kerkerte & 87 & 33 & 37.9 \\
Goroze & 42 & 9 & 21.29 \\
Addis Oltima & 21 & 4 & 19.04 \\
Lokite & 34 & 12 & 37.5 \\
Total & 384 & 139 & 36.19 \\
\hline
\end{tabular}

TABLE 4: Characters of the animal and prevalence of tick.

\begin{tabular}{|c|c|c|c|c|c|c|}
\hline \multicolumn{2}{|c|}{ Animal factors } & \multirow{3}{*}{$\begin{array}{c}\text { Frequency }(\mathrm{n}) \\
314 \\
70\end{array}$} & \multirow{3}{*}{$\begin{array}{c}\text { Tick infested } \\
109 \\
30 \\
\end{array}$} & \multirow{3}{*}{$\begin{array}{c}\text { Percentage (\%) } \\
34.7 \\
42.85 \\
\end{array}$} & \multirow{3}{*}{$\begin{array}{c}x^{2} \\
1.64\end{array}$} & \multirow{3}{*}{$\begin{array}{c}P \text { value } \\
0.200\end{array}$} \\
\hline & Young & & & & & \\
\hline Age & Old & & & & & \\
\hline \multirow{2}{*}{ Sex } & Male & 155 & 54 & 34.83 & 0.20 & 0.064 \\
\hline & Female & 229 & 85 & 37.11 & & \\
\hline \multirow{3}{*}{ BCS } & Good & 280 & 94 & 33.57 & 9.219 & 0.010 \\
\hline & Medium & 39 & 11 & 28.2 & & \\
\hline & Poor & 65 & 34 & 52.3 & & \\
\hline \multirow{3}{*}{ Breed } & Local & 380 & 137 & 35.67 & 1.77 & 0.411 \\
\hline & Exotic & 1 & 1 & 100 & & \\
\hline & Cross & 3 & 1 & 33.33 & & \\
\hline \multirow{2}{*}{ Season } & Wet & 148 & 65 & 43.9 & 6.216 & 0.013 \\
\hline & Dry & 236 & 74 & 31.35 & & \\
\hline Total & 384 & 139 & 36.19 & & & \\
\hline
\end{tabular}

than the report by Meseret et al. [36] who reported 59.6\% prevalence in Harari region, Eastern Ethiopia. This might be due to the difference in area coverage of the study area and agroecology. It might also be due to a variation in acaricide application and access to acaricide as by Nath et al. [37] and the method of application of acaricides [38], as chemical acaricide is the main weapon for the control of ticks.

Tick infestation was reported in different parts of Ethiopia and is higher as compared to the finding of the current study, the finding of Mesfin et al. [39] (89.1\%) in Wolaita Zone, the finding of Kumisa et al. [40] (68.8\%) in Dandi district, Oromia, the finding of Kemal et al. [41] (75.7\%) in Arbegona district, and the finding of Wasihun and Doda [42] (61\%) in Humbo district. The difference in prevalence could be attributed to the difference in environmental factors such as humidity which are conducive for survival and growth of tick developmental stages, and reproduction of ticks varying among study areas. 
TABLE 5: Host factors and prevalence of haemoparasites.

\begin{tabular}{|c|c|c|c|c|c|c|}
\hline \multicolumn{2}{|c|}{ Animal factor } & \multirow{2}{*}{$\begin{array}{c}\text { Frequency }(\mathrm{n}) \\
314\end{array}$} & \multirow{2}{*}{$\begin{array}{c}\text { Infected } \\
17\end{array}$} & \multirow{2}{*}{$\begin{array}{c}\text { Percentage (\%) } \\
5.41\end{array}$} & \multirow{2}{*}{$\frac{x^{2}}{3.402}$} & \multirow{3}{*}{$\begin{array}{c}P \text { value } \\
0.065\end{array}$} \\
\hline A go & Young & & & & & \\
\hline Age & Old & 70 & 8 & 11.4 & & \\
\hline \multirow{2}{*}{ Sex } & Male & 155 & 11 & 7.096 & 0.146 & 0.702 \\
\hline & Female & 229 & 14 & 6.11 & & \\
\hline \multirow{3}{*}{ BCS } & Good & 280 & 18 & 6.43 & 3.81 & 0.149 \\
\hline & Medium & 39 & 5 & 12.8 & & \\
\hline & Poor & 65 & 2 & 3.07 & & \\
\hline \multirow{3}{*}{ Breed } & Local & 380 & 25 & 6.51 & 0.728 & 0.869 \\
\hline & Exotic & 1 & 0 & 0 & & \\
\hline & Cross & 3 & 0 & 0 & & \\
\hline \multirow{2}{*}{ Tick infestation } & Yes & 139 & 20 & 14.38 & 22.2 & 0.000 \\
\hline & No & 245 & 5 & 2.04 & & \\
\hline \multirow{2}{*}{ Season } & Wet & 148 & 14 & 9.46 & 3.44 & 0.064 \\
\hline & Dry & 236 & 11 & 4.66 & & \\
\hline Total & 384 & 25 & 6.51 & & & \\
\hline
\end{tabular}

Environmental factors which support tick survival in the specific area include temperature, humidity, rainfall [43], vegetation [44], host availability, and season [45]. The variation in prevalences of tick infestation could be also due to variation in animal husbandry and management among the areas, as management found to affect tick prevalence as described by Soberanes-Céspedes et al. [46].

The finding of the current study is also lower than the report of Kemal and Abera [5] who reported $72.1 \%$ in Dassenech district, Southern Ethiopia. This could be due to the variation in host range and diversity of wild life between study areas, where in the later, there were high interaction of domestic and wild animals. Peter et al. [47] signified that wild herbivores support a large number of tick species, and Tonetti et al. [48] also described that wild herbivores are believed to be significant reservoirs of tick-borne pathogens.

Regarding the preference of ticks to different sexes of animals, Yakubu et al. [49], Utech and Wharton [50], and Burrow et al. [51] reported high prevalence of tick infestation in male than female animals which is in agreement with the current finding. In the current study area, male animals move from place to place for searching of feed and in this process get infested with ticks, while female animals confined to home for breeding and milking purpose in the respective study areas could had been contributed to the differences in tick occurence between species.

Previous studies in Egypt [52-54], in Pakistan, and [55] in Ethiopia reported a higher prevalence of ticks in exotic breeds, which is in agreement to the current study. But in the current study, only 1 exotic and 3 crossbreeds were observed, and, it is not a sufficient sample size to compare and make interpretation. Although the mechanism of resistance acquired against tick infestation by indigenous breeds is not fully understood, it could be attributed to preimmunity against ectoparasites, which often established through contacts with the parasites at the early stage of their life [52].

Overall prevalence of haemoparasites was 25 (6.51\%), and only Babesia bovis species was identified as haemmoparasite. This finding is not in line with the reports of studies by Bariso and Worku [56] who reported $11.4 \%$ overall haemoparasitemia in Arsi, Central Ethiopia, Lemma et al. [57] who reported $23 \%$ in Jimma, and Alemayehu [58] who reported $12 \%$ in Jimma, Western Ethiopia. This variation could be attributed to differences in the study area, the level of animal's exposure to ticks (depending on the type of management), and the land use of the area, which are different amongthe study areas.

The prevalence of babesiosis in the current study is in agreement with the report of Ahmad and Hashim [59] who reported $6.6 \%$ prevalence from Pakistan and different researchers from different parts of Ethiopia. Lower prevalence of bovine babesiosis in Ethiopia was reported by Bariso and Worku [56] (1.3\%) and Shane et al. [60] (1.6\%) in Arsi, Wodajnew et al. [61] (1.24\%) in Benishangul Gumuz, Sitotaw et al. [62] (0.3\%) in Debrezeit, Ethiopia, and Ola-Fadunsin et al. [63] (1.2\%) in Nigeria. The differences in prevalence of babesiosis in cattle could be due to the type of diagnosis followed and the differences in different seasons of the year, as it is affected by the tick infestation state [64].

The finding of current study is an alarm for the local policy makers and administrators of the veterinary services, as ticks were not considered to be prevalent and ignored in the livestock diseases causation. Thus, the authors strongly advise that there should be preparedness in diagnosing tickborne diseases and avail treatment options for the tick-borne diseases, at least for babesiosis.

\section{Conclusion and Recommendations}

In conclusion, $36.19 \%$ overall prevalence of ticks and $6.51 \%$ prevalence of babesiosis is high enough to be responsible for loss of production, particularly the skin and hide, as there were no prevention and control in place. To this end, tick control in Alle district should be considered, and appropriate preparedness should be in place in the veterinary service delivery system for the diagnosis and treatment of tick-borne diseases. 


\section{Data Availability}

The data used to support the findings of this study are available at Hawassa University and Alle District Livestock and Fisheries Resources Development Bureau.

\section{Conflicts of Interest}

The authors declare that they have no conflicts of interest.

\section{Acknowledgments}

The authors would like to acknowledge the staff of Alle District Veterinary Clinic and cattle owners for cooperating in execution of this research.

\section{References}

[1] CSA, Agricultural Sample Survey. Report on Livestock and Livestock Characteristics (Private Peasant Holdings), Vol. 1, Central Stastistical Agenecy (CSA), Addis Ababa, Ethiopia, 2015.

[2] D. Befikadu and N. Berhanu, Annual Report on the Ethiopian Economy VOLL 1999/2000, Ethiopian Economic Association, Addis Ababa, Ethiopia, 2000.

[3] J. M. Olwoch, B. Revers, and A. S. Vanjaarsveld, "Host parasitic distribution patterens under simulated climate," International Journal of Current Research, vol. 4, pp. 73-76, 2009.

[4] T. Ayalew, Y. Hailu, and B. Kumsa, "Ixodid tick infesting cattle in three agro ecological zones in central Oromia: species composition, seasonal variation, and control practices," Comparative Clinical Pathology, vol. 23, pp. 1103-1110, 2014.

[5] J. Kemal and T. Abera, "Prevalence and infestation load of ixodid ticks of cattle in Dassenech district, southern Ethiopia," Ethiopian Veterinary Journal, vol. 21, no. 2, pp. 121-130, 2017.

[6] M. Wanjira, "Phenotypic and molecular characterization of hard ticks (Acari: Ixodidae) sampled from wild herbivores from lake Nakuru and Tsavo national parks in Kenya," thesis, Kenyatta University, p. 1, Nairobi, Kenya, 2015.

[7] J. J. De Castro, AD. James, B. Minjauw et al., "Long-term studies on the economic impact of ticks on Sanga cattle in Zambia," Experimental and Applied Acarology, vol. 21, no. 1, pp. 3-19, 1997.

[8] A. Walker, A. Bouttour, J. Camicas, A. Estrada-Pena, I. Horak, and A. Latif, Ticks of Domestic Animals in Africa: A Guide to Identification of Species, Bioscience Report, Edinburg, TX, USA, 2003.

[9] G. Solomon, M. Night, and B. Kassa, "Seasonal variation of tick on calves at Sebeta in western Shewa zone," The Ethiopian Veterinary Journal, vol. 7, pp. 17-30, 2001.

[10] B. Tadesse and A. Sultan, "Prevalence and distribution of tick infestation on cattle at Fitche Selale, north Shewa, Ethiopia," Livestock Research for Rural Development Journal, vol. 26, no. 8, pp. 1-8, 2014.

[11] S. Mekonnen, I. Hussein, and B. Bedane, "The distribution of ixodid ticks (Acari: Ixodidae) in central Ethiopia," Onderstepoort Journal of Veterinary Research, vol. 68, no. 4, pp. 243-251, 2001.

[12] R. G. Pegram, H. Hoogstraal, and H. Y. Wassef, "Ticks (Acari: Ixodidae) of Ethiopia. Distribution, ecology and relation of species infesting livestock," Bulletin of Entomology Research, vol. 71, no. 3, pp. 335-359, 1981.
[13] A. Regassa, "The use of herbal preparations for tick control in western Ethiopia," Journal of the South African Veterinary Association, vol. 71, no. 4, pp. 240-243, 2000.

[14] J. Yilma, G. Adamu, and E. Zerbini, "Biossay of acaricide resistance on three common cattle tick species at Holotta, Central Ethiopia," Revue de Médecine Vétérinaire, vol. 152, no. 5, pp. 385-390, 2001.

[15] L. H. Makala, P. Mangani, K. Fujisaki, and H. Nagasawa, "The current status of major tick borne diseases in Zambia," Veterinary Research, vol. 34, no. 1, pp. 27-45, 2003.

[16] O. M. Radostits, C. C. Gay, K. W. Hinchcliff, and P. D. Constable, "Mastits. In: Veterinary Medicine: A Text Book of Disease of Cattle," Sheep, Pigs, Goats, and Horses, pp. 674-762, Ballier Tindall, London, UK, 10th edition, 2007.

[17] N. Gul, S. Ayaz, I. Gul, M. Adnan, S. Shams, and N. Akbar, "Tropical theileriosis and east coast fever in cattle: present, past and future perspective." International Journal of Current Microbiology and Applied Sciences, vol. 4, pp. 1000-1018, 2015.

[18] B. OIE, Manual of Diagnostic Tests and Vaccines for Terrestrial Animals: Mammals, Birds and Bees, Vol. 5, Office International des Âepizooties, Paris, France, 2015.

[19] H. Gebrekidan, A. Hailu, A. Kassahun et al., "Theileria infection in domestic ruminants in northern Ethiopia," Veterinary Parasitology, vol. 200, no. 1-2, pp. 31-38, 2014.

[20] A. Rymaszewska and S. Grenda, "Bacteria of the genus Anaplasma, characteristics of Anaplasma and their vectors: a review," Veterinarni Medicina, vol. 53, no. 11, pp. 573-584, 2008.

[21] C. M. Kahn, The Merck Veterinary Manualpp. 18-32, Merck and Company Incorporated, Kenilworth, NJ, USA, 9th edition, 2005.

[22] S. M. Chen, J. S. Dumler, J. S. Bakken, and D. H. Walker, "Identification of a granulocytotropic Ehrlichia species as the etiologic agent of human disease," Journal of Clinical Microbiology, vol. 32, no. 3, pp. 589-595, 1994.

[23] M. Y. Ramadan, L. M. Elakabawy, R. S. Elmadawy, and M. M. Kamal, "Prevalence of hard tick infesting cattle with a special reference to microscopic and molecular early diagnosis of tick born piroplasms." Benha Veterinary Medical Journal, vol. 30, no. 2, pp. 51-60, 2016.

[24] J. F. Hammer, C. Jenkins, D. Bogema, and D. Emery, "Mechanical transfer of Theileria orientalis: possible roles of biting arthropods, colostrum and husbandry practices in disease transmission,” Parasite Vectors, vol. 9, p. 34, 2016.

[25] J. Lodos, O. Boue, and J. de la Fuente, "A model to simulate the effect of vaccination against Boophilus ticks on cattle," Veterinary Parasitology, vol. 87, no. 4, pp. 315-326, 2000.

[26] C. Le Bars, Tick Borne Diseases Management, Veterinary Times, Peterborough, UK, 2009.

[27] K. I. Kasozi, E. Matovu, D. S. Tayebwa, J. Natuhwera, I. Mugezi, and M. Mahero, "Epidemiology of increasing hemo-parasite burden in Ugandan cattle," Open Journal of Veterinary Medicine, vol. 4, no. 10, pp. 220-231, 2014.

[28] A. Y. Hasen, T. M. Yemane, Y. Bekele, M. Abebe, and Z. Ejigu, "Identification of encountered bovine tick species in and around Gambela town," American Journal of Entomology, vol. 1, no. 1, pp. 1-5, 2017.

[29] A. Jabbar, T. Abbas, Z. U. D. Sandu, H. A. Saddiqi, M. F. Qamar, and R. B. Gasser, "Tick borne diseases of bovines in Pakistan. Major scope for future research and improved control," Parasite Vectors, vol. 8, p. 283, 2015.

[30] F. D. Wesonga, P. M. Kitala, J. M. Gathuma, M. J. Njenga, and P. N. Ngumi, "An assessment of tick-borne diseases constraints to livestock production in a smallholder livestock 
production system in Machakos district," Livestock Research for Rural Development, vol. 22, Article ID 111, 2010.

[31] Alle Woreda Agriculture and Natural Resource Office, Annual Report on Agricultrual Production and Productivity, Kore, Alle, Ethiopia, 2019.

[32] M. Thrusfield, "Sample size determination," Veterinary Epidemiology, vol. 3, pp. 185-189, 2007.

[33] M. Bitew, Y. Amediem, A. Abebe, and T. Tolosa, "Prevalence of bovine trypanosomosis in selected areas of Jabi Tehenan district, West Gojam of Amhara regional state, Northwestern Ethiopia," African Journal of Agricultural Research, vol. 6, pp. 140-144, 2011.

[34] J. Nicholson and M. H. Butterworth, A Guide to Condition Scoring of Zebu Cattle, International Livestock Center for Africa, Addis Ababa, Ethiopia, 1986.

[35] R. Bock, L. Jackson, A. De Vos, and W. Jorgensen, "Babesiosis of cattle," Parasitology, vol. 129, no. S1, pp. S247-S269, 2004.

[36] M. Meseret, D. Tilaye, and W. Akinaw, "Study on prevalence of major ixodid ticks of cattle in selected sites of Harari region, eastern Ethiopia," Ecology and Evolutionary Biology, vol. 2, no. 6, pp. 96-100, 2017

[37] S. Nath, S. Mandal, S. Pal, S. Jadhao, N. Ottalwar, and P. K. Sanyal, "Impact and management of acaricide resistance: pertaining to sustainable control of ticks," International Journal of Livestock Research, vol. 8, no. 10, pp. 46-60, 2018.

[38] M. W. Bianchi, N. Barré, and S. Messad, "Factors related to cattle infestation level and resistance to acaricides in Boophilus microplus tick populations in New Caledonia," Veterinary Parasitology, vol. 112, no. 1-2, pp. 75-89, 2003.

[39] M. Mesfin, S. Tewedros, and Y. Yemisrach, "Study on the ixodid ticks of domestic ruminants in three selected districts of Wolaita zone, southern Ethiopia," Global Journal of Science Frontier Research: D Agricultural and Veterinary, vol. 18, pp. 32-38, 2018.

[40] M. Kumisa, H. Geremew, M. Negesse, and F. Walkite, "Prevalence and identification of bovine ixodid tick in Dandi district, west Shoa zone, Oromia, region, Ethiopia," SOJ Veterinary Sciences, vol. 3, no. 5, pp. 1-8, 2017.

[41] J. Kemal and T. Abera, "Prevalence and infestation load of ixodid ticks of cattle in Dassenech district," Southern Ethiopia, Ethiopian Veterinary Journal, vol. 21, no. 2, pp. 121-130, 2017.

[42] P. Wasihun and D. Doda, "Study on prevalence and identification of ticks in Humbo district, SNNPR, Ethiopia," Journal of Veterinary Medicine and Animal Health, vol. 5, no. 3, pp. 73-80, 2013.

[43] B. P. J. Greenfield, "Environmental parameters affecting tick (Ixodes ricinus) distribution during the summer season in Richmond Park, London," Bioscience Horizons, vol. 4, no. 2, pp. 140-148, 2011.

[44] J. S. Gray, "Biology of ixodes species ticks in relation to tickborne zoonosis," Wiener Klinische Wochenschrift, vol. 114, no. 13-14, pp. 473-478, 2002.

[45] P. D. Teel, S. L. Marin, and W. E. Grant, "Simulation of host parasite land scape interactions: influence of season and habitat on cattle fever tick (Boophilus spp.) population dynamics," Ecological Modelling, vol. 84, no. 1-3, pp. 19-30, 1996.

[46] N. Soberanes-Céspedes, R. Rosario-Cruz, V. M. Santamaría, and Z. García-Vazquez, "General esterase activity variation in the cattle tick, Boophilus microplus \& its relationship with organophosphate resistance," Tecnica Pecuaria en Mexico, vol. 43, no. 2, pp. 239-246, 2005.

[47] T. F. Peter, E. C. Anderson, M. J. Burridge, and S. M. Mahan, "Demostration of a carrier state for Cowdria ruminantium in wild ruminants from Africa," Journal of Wildlife Diseases, vol. 34, no. 3, pp. 567-575, 1998.

[48] M. S. Tonetti, "Periodontitis and risk for atherosclerosis: an update on intervention trials," Journal of Clinical Periodontology, vol. 36, pp. 15-19, 2009.

[49] A. Yakubu, A. Yahaya, and J. N. Omeje, "Heat tolerance traits and tick infestation in some indigenous breeds of cattle in Nigeria," Slovak Journal of Animal Science, vol. 48, no. 2, pp. 79-85, 2015.

[50] K. B. Utech and R. H. Wharton, "Breeding for resistance to Boophilus microphilus in Australian illawara short horn and Brahman X Australian illawara short horn cattle," Australian Veterinary Journal, vol. 58, no. 2, pp. 41-46, 1982.

[51] H. Burrow, G. W. Seifert, and D. J. S. Hetzel, "Consequences of selection for weaning weight in zebu, Bos taurus and zebu $\times$ Bos taurus cattle in the tropics," Australian Journal of Agricultural Research, vol. 42, no. 2, pp. 295-307, 1991.

[52] S. Ahmed, M. Numan, A. W. Manzoor, and F. A. Ali, "Investigations into ixodidae ticks in cattle in Lahore, Pakistan," Veterinaria Italiana, vol. 48, no. 2, pp. 185-191, 2012.

[53] N. M. Asmaa, M. El Bably, and K. A. Shokier, "Studies on prevalence, risk factors and control options for tick infestation in ruminants," Beni-Suef University Journal of Basic and Applied Sciences, vol. 3, no. 1, pp. 68-73, 2014.

[54] M. S. Sajid, Z. Iqbal, M. N. Khan, G. Muhammad, and M. K. Khan, "Prevalence and associated risk factors for bovine tick infestation in two districts of lower Punjab, Pakistan," Preventive Veterinary Medicine, vol. 92, no. 4, pp. 386-391, 2009.

[55] G. Solomon and G. P. Kaaya, "Comparison of resistance in three breeds of cattle against African ixodid ticks," Experimental and Applied Acarology, vol. 20, no. 4, pp. 223-230, 1996.

[56] M. Bariso and Y. Worku, "Cattle ticks and tick borne haemoparasite species identification and associated risk factors in two districts of West Arsi Zone, Ethiopia," Journal of Veterinary Science and Animal Husbandry, vol. 6, no. 5, p. 501, 2018.

[57] F. Lemma, A. Girma, and D. Demam, "Prevalence of bovine babesiosis in and around Jimma town, South western Ethiopia," Advances in Biological Research, vol. 9, pp. 338439, 2016.

[58] C. Alemayehu, "Study on bovine babesiosis and its associatted risk factors in and around Jimma town, southwest Ethiopia," DVM thesis, Jimma University, p. 38, Jimma, Ethiopia, 2014.

[59] N. Ahmad and H. Hashim, "A comparative study on the incidence of ticks and ticks borne diseases on local and crossbred cattle in Malakand agency," Journal of Animal and Plant Sciences, vol. 17, pp. 56-58, 2007.

[60] T. Shane, T. Gunse, and F. T. Woldemariyam, "Identification of tick and tick borne hemo-parasites in Tiyo district, Arsi zone, Oromia region," Journal of Veterinary Science \& Technology, vol. 8, p. 418, 2017.

[61] B. Wodajnew, H. Disassa, T. Kabeta, T. Zenebe, and G. Kebede, "Study on the prevalence of bovine babesiosis and its associated risk factors in and around Assosa Woreda, Benishangul Gumuz regional state, western Ethiopia," Researcher, vol. 7, no. 8, pp. 28-32, 2015.

[62] T. Sitotaw, F. Regassa, F. Zeru, and A. G. Kahsay, "Epidemiological significance of major hemoparasites of ruminants in and around Debre-Zeit, Central Ethiopia," Journal of Parasitology and Vector Biology, vol. 6, pp. 16-22, 2014. 
[63] S. D. Ola-Fadunsin, I. A. Ganiyu, K. Hussain, and M. Rabiu, "Occurrence of parasitic diseases of horses in Osun state, Nigeria: a retrospective evaluation," Alexandria Journal for Veterinary Sciences, vol. 56, no. 1, pp. 175-181, 2018.

[64] S. Almería, J. Castellà, D. Ferrer, A. Ortuño, A. Estrada-Peña, and J. F. Gutiérrez, "Bovine piroplasms in Minorca (Balearic Islands, Spain): a comparison of PCR-based and light microscopy detection," Veterinary Parasitology, vol. 99, no. 3, pp. 249-259, 2001. 